\title{
Blood Pressure Measurement Training Program and Adherence of Public Health Nurses to BP Measurement Guidelines
}

\author{
Jesusa S. Pagsibigan, ${ }^{1}$ Araceli O. Balabagno, ${ }^{1}$ Josefina A. Tuazon $^{1}$ and Lorraine S. Evangelista ${ }^{1,2}$ \\ ${ }^{1}$ College of Nursing, University of the Philippines Manila \\ ${ }^{2}$ Sue and Bill Gross School of Nursing, University of California Irvine, Irvine, California, USA
}

\begin{abstract}
Objective. To compare the level of adherence of public health nurses to BP measurement guidelines based on their knowledge of the guidelines and skills in BP measurement before and after Blood Pressure Measurement Training Program (BPMTP).

Methods. An experimental pre- and post-test design using twostaged cluster randomization was conducted. 118 PHNs (mean age \pm 38.45 years, mean years of experience \pm 13.45 years; $84.1 \%$ women) from six districts in Manila were equally assigned to either the BPMTP group or control group. Structured instruments were used.

Results. Demographic characteristics, current BP measurement practices, and level of adherence to BP measurement guidelines based on knowledge of the guidelines and skills in BP measurement were equivalent in both groups at baseline. Nurses in the BPMTP group showed improved adherence $(p=<0.05)$ compared to nurses in the control group. Both groups did not show significant change in their skill on recording, interpretation, and referral $(p=1.000)$.
\end{abstract}

Conclusion. This study showed that Blood Pressure Measurement Training Package is feasible in improving adherence of nurses based on their increased knowledge of the BP measurement guidelines and skills in BP measurement. A larger-scale study is warranted to show that BPMTP can potentially improve clinical management of hypertension in public health clinics globally.

Key Words: BP measurement guidelines, adherence, training program, public health nurses

Presented at the 4th UP Honor Society and UPCN Research Forum, May 9, 2017, UP College of Nursing Seminar Room; and at the 17th East Asia Forum Of Nurses (EAFONS) International Conference, February 20, 2014, Century Park Hotel, Manila.

Corresponding author: Jesusa S. Pagsibigan, MAN, RN

College of Nursing

University of the Philippines Manila

3rd Floor Sotejo Building, Pedro Gil St., Ermita, Manila 1000 Philippines

Telephone: +632 5231472

Email: jspagsibigan@up.edu.ph

\section{Introduction}

Public health nurses (PHNs) are explicitly required to perform accurate assessment, screening, and monitoring which include blood pressure (BP) measurement. ${ }^{1}$ BP measurement is the only assessment tool that confirms the diagnosis of and classifies individuals with hypertension, ascertains BP-related risks, guides interventions for BP control, and appraises intervention outcomes. ${ }^{2-5}$ Decades of studies reveal practice variations in BP measurement and the lack of adherence to BP measurement guidelines; ${ }^{6-10}$ these compromise accuracy of $\mathrm{BP}$ readings and results to reduced prevention, diagnosis, and control of hypertension, poor disease outcomes, high cost of care, and premature mortality. ${ }^{11-16}$

Studies conducted among health professionals who perform BP measurements revealed common pitfalls and lack of adherence to guidelines. There is a general consensus among the studies on BP measurement that strongly recommend regular training and retraining of health care professionals on BP measurement. ${ }^{3,4,17-22}$ Educational intervention based on guidelines improved BP measurement skills and knowledge. $6,7,14,17,19,20,23,24$

There are no known major studies in the Philippines related to practice variations, and adherence to BP measurement guidelines. There is also a dearth of literature on evaluation studies of intervention outcomes on adherence to BP measurement guidelines by health professionals.

This study determined the level of adherence of PHNs to $\mathrm{BP}$ measurement guidelines before and after the BP Measurement Training Program (BPMTP). This study refers to adherence as the knowledge and BP measurement skills of PHNs following the guidelines specified in the BP Measurement Guidelines Manual (BPMGM), an essential component of the Blood Pressure Measurement Training Program.

Guided by Roy's Adaptation Model, ${ }^{21-22}$ the response elicited by the stimulus BPMTP should find congruence to one or all of their adaptation modes: 1) capability to adapt to the expected behaviour, 2) value of the behaviour to self/team, 3) value of the behaviour to the community, and 4) value of professional collaboration, and alliance. Figure 1 illustrates how the educational intervention could increase the level of adherence of PHNs to BP measurement guidelines. 


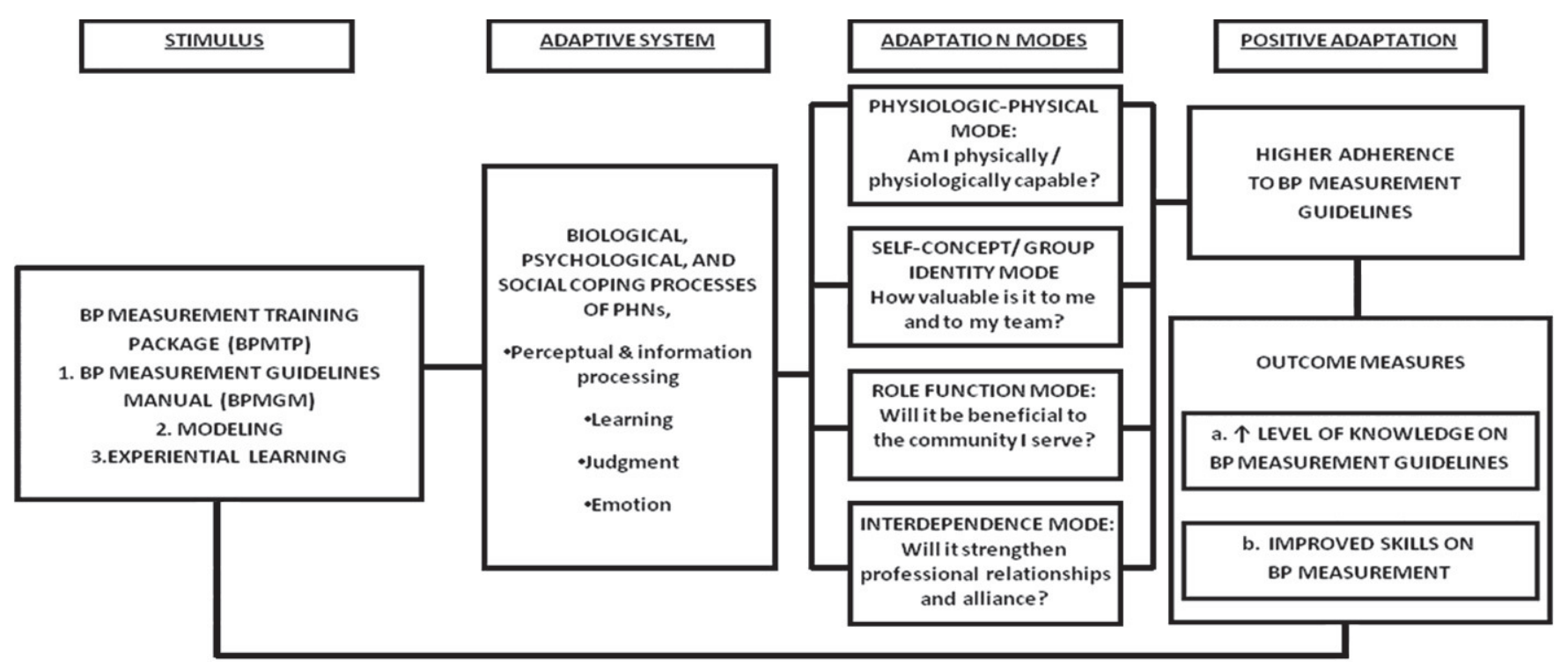

Figure 1. Theoretical Paradigm (Roy, 1970/1984). Blood Pressure Management Training Package (BPMTP) integrates three components: 1. BP Measurement Guidelines Manual (BPMGM) - the scientific evidence, 2. Modeling the procedure based on the guidelines, and 3. Experiential learning with peers. The stimulus, BPMTP, initiates a response from the PHN (adaptive system) who utilizes inherent biological, psychological and social coping processes to analyze information, make judgement, become aware of associated feelings/emotions, and learn to respond towards positive adaptation/BP measurement that adheres to the guidelines when response is congruent to one or all of the adaptation modes - Physiologic-physical capability, value of the action individually/the team, value to the community they serve, and value to professional relationships and alliance. The outcome measures of positive adaptation/BP measurement that adheres to the guidelines are a) knowledge of BP measurement guidelines and b) skills in BP measurement.

\section{Significance of the Study}

Standardized care (i.e., BP measurement based on guidelines), is integral to nursing education, quality care, and safe nursing practice.

Adherence to guidelines reduces inaccuracies that may expose the patient to misdiagnosis and inappropriate care. ${ }^{11-16}$ Therefore, BP measurement based on guidelines becomes truly a valuable tool in screening for high risk patients, early detection and control of hypertension, and prevention of complications. Recognition of practice variations, and common pitfalls would help motivate nurses to pay attention to current guidelines and narrow the gap between theory and practice.

\section{Methods}

\section{Design}

An experimental, pre - and post - test design was used to determine the level of adherence to BP measurement guidelines among public health nurses (PHNs). Two-stage cluster sampling method was applied using unmarked ballots, and two non-transparent boxes, one marked "Intervention" and the other marked "Control."

\section{Sample Selection}

The study participants are PHNs working for the government specifically in the health centers, clinics, city high schools, and special services units who are mandated to address pressing health problems in the City of Manila. The 1st stage assigned all the health districts in Manila to either the intervention or the control group by simple random sampling. The intervention group (BPMTP) was drawn from Districts I, II, and VI; control group (no structured training) was drawn from Districts III, IV, and V.

The 2nd stage placed the names of all PHNs from the master list into appropriate ballot boxes. Using systematic random sampling, ballots were alternately drawn until computed sample size was completed. Randomizing by cluster allows investigators to measure the effectiveness of an intervention in routine clinical practice using clusters (rather than individuals) to create comparative groups. Sample size was determined using software G-power and the application of Cohen's power of $0.80, \alpha=0.05$, effect size of 0.30 , and an oversampling of $20 \%$ $(n=128)$. PHNs were excluded from the study if they did not have a functional BP measurement device in their unit or were not willing to participate in the study. Figure 2 illustrates the sample selection - a total of 128 PHNs were recruited from 194 PHNs from 6 districts in Manila; five nurses were excluded from each group resulting to 118 PHNs equally randomized to the BPMTP group $(n=59)$ or the control group $(n=59)$. Figure 2 illustrates the sample selection. 


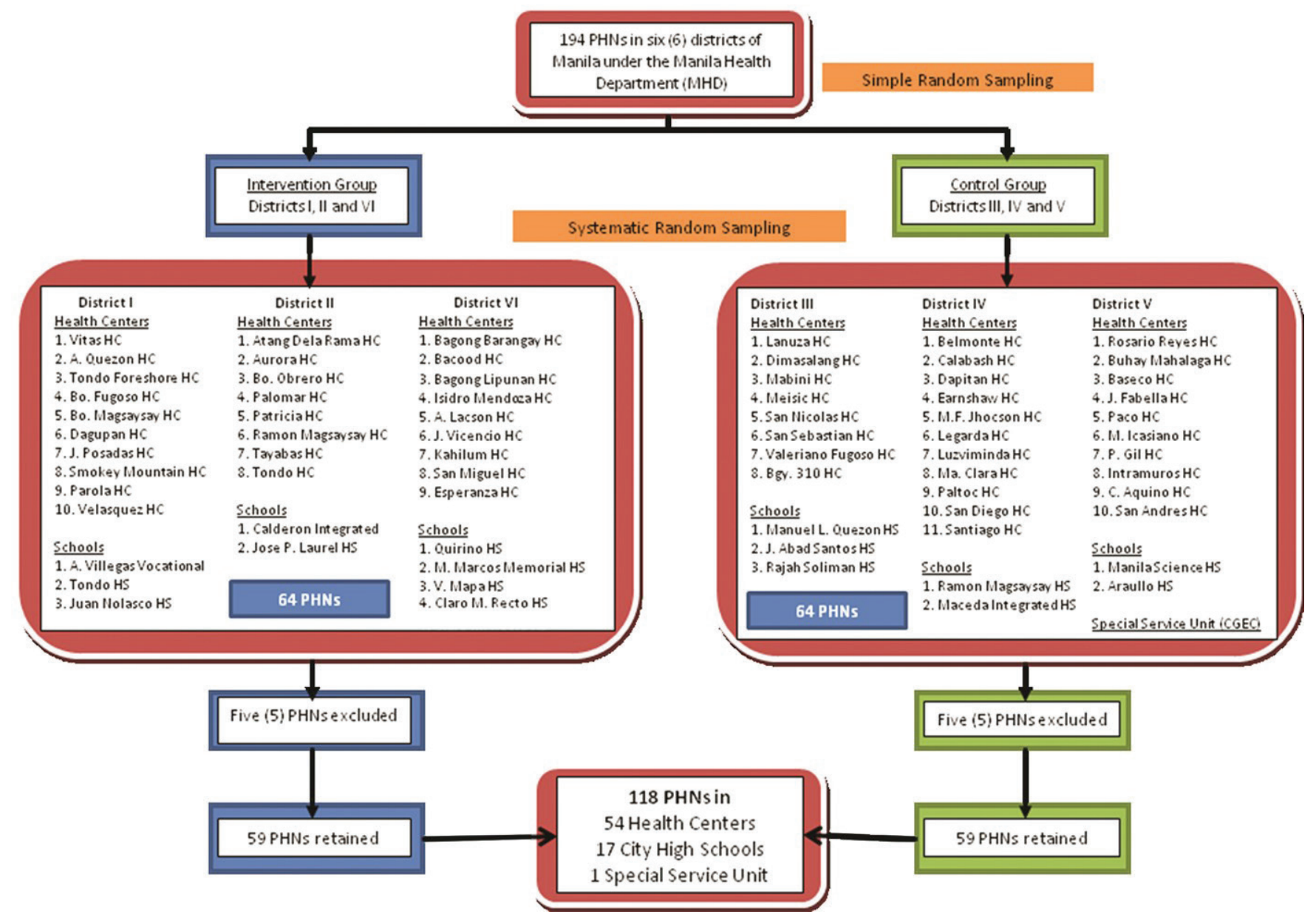

Figure 2. Sample Selection. Two-stage sampling design was used to select PHNs from a sampling frame (N=194) within the 6 Districts of Manila. The districts were assigned to the intervention (Districts I, II, VI) and the control (Districts III, IV, V) groups using simple random sampling. From the health centers, city high schools, and special services unit in both groups, study participants were selected using systematic random sampling ( $\mathrm{n}=128) .10$ PHNs were excluded based on the exclusion criteria. Final sample $(\mathrm{n}=118)$ was drawn from 57 health centers, 17 city high schools, and 1 Special Services Unit. Each group has the same number of sample $(I=59, C=59)$.

\section{Setting}

The study was conducted in all six districts of Manila where prevalence of non-communicable diseases is high and hypertension remains to be one of the major risk factor for cardiovascular diseases, stroke, and kidney disease.

In a country classified as one of the lower middleincome countries in the world, and like in any other cities in the Philippines, Manila has to contend with limited resources in the delivery of its health care services. ${ }^{23}$

\section{Instrumentation}

The following structured instruments were used. Respondent Profile Questionnaire; Blood Pressure Measurement Device Quality Checklist; ${ }^{19}$ Blood Pressure Measurement Skills Checklist; ${ }^{19}, 24$ and Blood Pressure Measurement Knowledge Test. ${ }^{919}{ }^{25}$ Table 1 provides a more in-depth description of each instrument.

\section{Pilot Testing}

Pilot testing was done in a similar urban setting, located in the National Capital Region. PHNs in this testing site provide health services to their constituents and are closely linked with the program of the Department of Health. The characteristics of their population and resources are similar. Tools were found to be simple and appropriate for the study. It also affirmed that the instruments were valid and reliable. The inter-rater reliability test using Cohen's Kappa showed 0.86 .

\section{Blood Pressure Measurement Training Program (BPMTP)}

BPMTP integrates three essential components to promote BP measurement that adheres to guidelines - 1) BP Measurement Training Manual (BPMTM) which is the source of scientific evidence for the program, 2) modeling of the BP measurement techniques based on guidelines, and 3) 
Table 1. Instruments used to measure the study variables

\begin{tabular}{|c|c|}
\hline Instruments & Description \\
\hline $\begin{array}{l}\text { 1. Respondent Profile } \\
\text { Questionnaire }\end{array}$ & $\begin{array}{l}\text { Provides data on characteristics of the study participants. } \\
\text { Part I - Socio-demographic data: age, sex, rank, length of nursing experience } \\
\text { Part } 2 \text { - BP measurement-related information: confidence level in the accuracy of BP measurement, awareness of BP measurement } \\
\text { guidelines, training and certification on BP measurement, knowledge on the type of BP devices used, tracking of regular calibration, } \\
\text { maintenance, and validation of BP measurement devices, number of patients seen daily, number of BP measurements done daily, } \\
\text { presence of physical-sensory limitations (hearing, vision, hand/arm mobility) }\end{array}$ \\
\hline $\begin{array}{l}\text { 2. BP Measurement } \\
\text { Device Checklist }{ }^{23}\end{array}$ & $\begin{array}{l}\text { Measures the capability of the study participant to check the accuracy of the BP measurement device. } \\
\text { - Type of device used (indicate serial number) } \\
\text { - Position/placement of the device } \\
\text { - Documentation of last Quality Assurance check } \\
\text { - Integrity of the BP cuff } \\
\text { - Tubing condition } \\
\text { - Device accuracy }\end{array}$ \\
\hline $\begin{array}{l}\text { 3. BP Measurement } \\
\text { Skills Checklist }^{23}\end{array}$ & $\begin{array}{l}\text { Evaluates the } 47 \text { essential steps in BP measurement based on guidelines. Each item is scored } 0 \text { for non-performance, } 2 \text { for a well- } \\
\text { performed step. A summative score was tallied at the end of the procedure. Each respondent is observed in taking BP measurements } \\
\text { in four (4) patients. They are observed in the following: } \\
\text { 1. Preparation for the procedure - patient preparation, patient positioning, and selection of cuff size } \\
\text { 2. Techniques - application of correct size BP cuff and use of stethoscope, palpation of estimated systolic BP, and BP reading by } \\
\text { auscultation } \\
\text { 3. Other guidelines for specific situations - 1st clinic visit, subsequent clinic visit, elevated 1st BP reading } \\
\text { 4. Recording, interpretation, and referral based on JNC } 7 \text { BP classification - significant details that require documentation as } \\
\text { reference for future consultation }\end{array}$ \\
\hline $\begin{array}{l}\text { 4. BP Measurement } \\
\text { Knowledge Test }{ }^{19,24,25,26}\end{array}$ & $\begin{array}{l}\text { A } 20 \text {-item test designed to evaluate the knowledge of the study participants on BP measurement guidelines } \\
\text { - Patient factors (6) } \\
\text { - Observer factors (5) } \\
\text { - Techniques (6) } \\
\text { - Equipment factors (3) }\end{array}$ \\
\hline
\end{tabular}

experiential learning with peers. This is designed as a prescheduled study time for the duration of 2.5 hours, held in an appropriate venue selected by nurse supervisors of the BPMTP group. A 90-minute lecture - demonstration was done by the primary author, followed by a 10-minute snack time. A 20-minute practice session and return demonstration was observed with the assistance of six trained research assistants who are all professional nurses with research background. Practical and written examination was performed after the practice sessions using the prescribed tool in this study. BPMTP group received a BPMGM handout after the program. BPMGM handout was also given to the control group upon completion of the evaluation phase.

BPMTP was evaluated by a panel comprised of the 1) Section of Hypertension Chairperson, Department of Medicine; 2) Adult Health Nurse Practitioner (Board Certified); 3) Nursing Quality Management System Coordinator (Nurse VI); and 4) Senior Trainor (Nurse IV). BP Measurement Guidelines Manual was evaluated as a reliable and important reference for PHNs. All other aspects of the training program, i.e. instructional design, and BPMGM handout were found to be appropriate, adequate, and easily understood. Its significance was connected to hypertension as the 3rd cause of morbidity in the Philippines, and PHNs as the primary health care givers of the Filipinos.

This educational intervention aims to improve the level of adherence to BP measurement guidelines by improving the level of knowledge of the guidelines and skills in BP measurement. Although confounding variables may affect the outcome of the study, attempt to control this was done using statistical treatment during data analysis.

\section{Data Collection Process}

The preparation for data collection included: 1) pretesting of instruments; 2) orientation and training of research team; 3) expert opinion; and 4) seeking ethical approval, official permit, and signing of informed consent by the study participants.

The data collection proper was done in three phases. Figure 3 illustrates the data collection process.

The research assistants were blinded to the groupings during Phase 1. Although all the RAs were involved in Phase 2 (Intervention Phase), in Phase 3 (Evaluation Phase) they were assigned to a different grouping from their previous assignment in Phase I. The individual scores of the nurses were also kept confidential from co-participants, and their heads.

\section{Data Analyses}

Descriptive statistics including means, ranges, standard deviations and $\chi 2$ statistics were used to characterize the study population. Perceived confidence, knowledge and adherence were compared between PHNs assigned to the BPMTP vs. the control group using the analysis of covariance statistic. First, we determined whether there were significant group differences in mean outcome scores over time. Then, to account for the possibility that similar group means might be found only because outcomes improved over time for 1 group while worsening for the other, we 


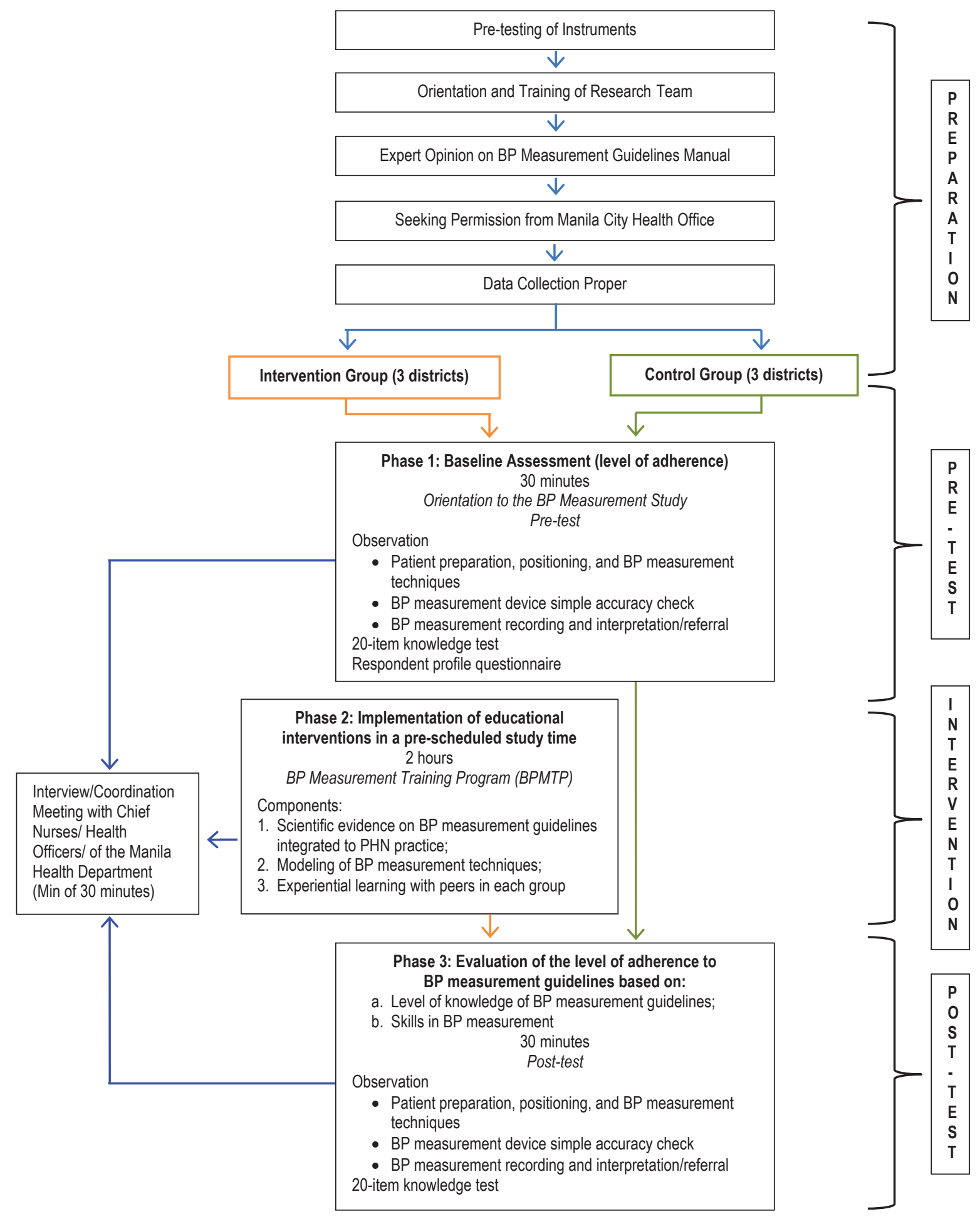

Figure 3. Flow Chart of Data Collection. This describes the four stages of the data collection process - preparation, pre-test, intervention, and post-test. Data was obtained using structured tools for observation and knowledge test.

conducted analyses of group $x$ time interactions. To control for the baseline group differences, we controlled for time 1 values by entering them as covariates in the analysis of covariance equation. The adjusted means presented herein account for the influence of time 1 value. All statistical analyses were carried out using SPSS for Windows (version 20; SPSS, Inc, Chicago, Illinois); statistical significance was set at $P<.05$ for all analyses. 


\section{Results and Discussion}

There is homogeneity in the demographic characteristics of the study participants $(p=>.05)$ as shown in Table 2. Their mean age, length of experience both as RNs and PHNs suggest substantial maturity among them which could imply that study participants are cut-out for their job since the role of PHNs is complex and broad, requiring varied competencies. ${ }^{1,26}$ Although predominantly female, there is a significant difference between groups in sex. This alerted the examiner to exercise caution when analyzing the data. The presence of physical-sensory limitations signals the risk for error in BP taking. The auscultatory method of $\mathrm{BP}$ measurement requires good coordination of hand/arm mobility with the eyes, and ears. A good sense of hearing is needed to hear the appearance of phase I, phase IV, and the disappearance of phase $\mathrm{V}$ of the Korotkoff sounds. ${ }^{4}$ In this study, participants with physical-sensory limitations declared interventions were done allowing them to still perform BP measurements.

Both groups are similar $(p=>.05)$ in terms of BP measurement-related confidence and practices, i.e., a mean confidence rate in taking $\mathrm{BP}$ measurement is 3 (in a 0-4 scale), generally without training or certification in BP measurement procedures, have not read any BP measurement guidelines within the last 2 years, mostly do not have their BP measurement device calibrated, use aneroid sphygmomanometer as the common measurement device, sees a wide range of patients daily, and performs a wide range of BP measurements per nurse daily. These data are summarized in Table 3.

Confidence level by the study participants is high which may relate to the fact that BP measurement is a simple, basic procedure which they have been doing routinely for the longest time. In one study, only a few nurses report some uncertainty about their confidence in BP taking (Armstrong 2002) ${ }^{6}$. Lack of awareness of BP measurement guidelines, and conformity to the standards of BP measurement result to practice variations that compromise accuracy $2,4,6,9,17,19,27$ leading to costly and deleterious consequences to the individual, their families, and to the nation. ${ }^{23,27-30}$

Tracking of BP measurement device validation/ calibration/maintenance is low among the study participants. The respondents assumed that machines purchased for them underwent validation testing and did not need testing. An observation of newer equipments showed no serial numbers, not zeroed " 0 " $\mathrm{mm} \mathrm{Hg}$, with pressure gauge unable to reach maximum inflation pressure smoothly. Further, there are no manuals, warranty card, and certification of machine validation available. In practice, there is no tracking logbook found in any of the study setting. This data implies that PHNs should be reminded on the need to examine BP measurement devices using a BP measurement device quality checklist based on guidelines. ${ }^{19,30}$
Table 2. Demographic characteristics of the intervention and control groups

\begin{tabular}{|c|c|c|c|}
\hline \multirow[t]{2}{*}{ Characteristics } & $\begin{array}{l}\text { Intervention } \\
\quad(n=59)\end{array}$ & $\begin{array}{c}\text { Control } \\
(n=59)\end{array}$ & \multirow[t]{2}{*}{$p$ value } \\
\hline & $f(\%)$ & $f(\%)$ & \\
\hline Age (mean years) $\ddagger$ & 38 & 37 & 0.49 \\
\hline \multicolumn{4}{|l|}{$\operatorname{Sex} \diamond$} \\
\hline Female Nurses & $45(78)$ & $53(90)$ & $0.05^{*}$ \\
\hline Male Nurses & $14(22)$ & $6(10)$ & \\
\hline Male-female ratio & $1: 3.5$ & $1: 9$ & \\
\hline 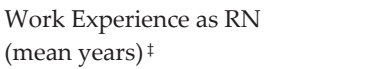 & 12 & 13 & 0.89 \\
\hline $\begin{array}{l}\text { Work Experience in current area } \\
\text { (mean years) } \ddagger\end{array}$ & 7 & 7 & 0.89 \\
\hline \multicolumn{4}{|l|}{ Position $\diamond$} \\
\hline Junior Nurses & $37(63)$ & $34(58)$ & 0.53 \\
\hline Senior Nurses & $22(37)$ & $25(42)$ & \\
\hline \multicolumn{4}{|l|}{ Physical-Sensory Limitations $\diamond$} \\
\hline Hearing & $0(0)$ & $1(2)$ & 0.16 \\
\hline Vision & $19(32)$ & $19(32)$ & 0.08 \\
\hline Hand/arm mobility & $2(3)$ & $2(3)$ & 0.32 \\
\hline
\end{tabular}

Note: $\ddagger$ Independent $\mathrm{t}$-test $\diamond$ Chi-square test $X^{2}$ test

* Statistically significant at $\alpha-0.05$

Table 3. BP measurement-related confidence and practices of the intervention and control groups

\begin{tabular}{|c|c|c|c|}
\hline Characteristics & $\begin{array}{c}\text { Intervention } \\
\mathbf{f}(\%)\end{array}$ & $\begin{array}{l}\text { Control } \\
\mathrm{f}(\%)\end{array}$ & $p$ value \\
\hline \multicolumn{4}{|l|}{$\begin{array}{l}\text { Level of confidence in performing } \\
\text { accurate BP measurement }\end{array}$} \\
\hline Strongly disagree (0) & $0(0)$ & $0(0)$ & 0.36 \\
\hline Disagree (1) & $1(2)$ & $1(2)$ & \\
\hline Unsure (2) & $2(4)$ & $2(4)$ & \\
\hline Agree (3) & $38(68)$ & $36(64)$ & \\
\hline Strongly agree (4) & $15(27)$ & $19(34)$ & \\
\hline Mean confidence rate & 3.18 & 3.07 & \\
\hline \multicolumn{4}{|l|}{ Training/Certification in } \\
\hline BP Measurement & $1(2)$ & $5(9)$ & 1.00 \\
\hline Yes & $58(98)$ & $53(91)$ & \\
\hline No & & & \\
\hline \multicolumn{4}{|l|}{$\begin{array}{l}\text { Reading BP measurement } \\
\text { guidelines (past } 2 \text { years) }\end{array}$} \\
\hline Yes & $10(17)$ & $11(19)$ & 1.00 \\
\hline No & $49(83)$ & $48(81)$ & \\
\hline $\begin{array}{l}\text { validation/calibration/ } \\
\text { maintenance tracking }\end{array}$ & $10(18)$ & $18(31)$ & 0.68 \\
\hline Yes & $48(8)$ & $40(69)$ & \\
\hline No & & & \\
\hline \multicolumn{4}{|l|}{ Common BP measurement device } \\
\hline Aneroid (portable) & $51(81)$ & $50(93)$ & 0.71 \\
\hline Aneroid (wall type) & $4(7)$ & $1(2)$ & \\
\hline Mercurial (portable) & $2(3)$ & $3(6)$ & \\
\hline \multicolumn{4}{|l|}{ Patient seen daily } \\
\hline$\leq 15$ patients & $20(34)$ & $12(20)$ & 0.99 \\
\hline $16-30$ patients & $12(20)$ & $12((20)$ & \\
\hline $31-50$ patients & $11(19)$ & $12(20)$ & \\
\hline$>50$ patients & $12(20)$ & $17(29)$ & \\
\hline \multicolumn{4}{|l|}{ BP measurements performed daily } \\
\hline$\leq 15$ BP measurements & $15(25)$ & $28(47)$ & 0.99 \\
\hline 16 - 30 BP measurements & $9(15)$ & $16(27)$ & \\
\hline 31 - 50 BP measurements & $18(30)$ & $6(10)$ & \\
\hline > 50 BP measurements & $11(19)$ & $4(7)$ & \\
\hline
\end{tabular}

* Statistically significant at $\alpha=0.05$ 
BP Measurement and Adherence

Table 4. Baseline adherence to BP measurement guidelines between intervention and control groups

\begin{tabular}{|c|c|c|c|c|c|c|}
\hline Outcome Variable & $\begin{array}{c}\text { Intervention } \\
\text { Mean Rank \% }\end{array}$ & $\begin{array}{l}\text { Standard } \\
\text { Deviation }\end{array}$ & $\begin{array}{c}\text { Control } \\
\text { Mean Rank \% }\end{array}$ & $\begin{array}{l}\text { Standard } \\
\text { Deviation }\end{array}$ & $\begin{array}{c}\text { Mean } \\
\text { Difference }\end{array}$ & $p$-value \\
\hline I - Knowledge of BP measurement guidelines & 56.83 & 2.31 & 62.17 & 2.64 & 5.34 & .240 \\
\hline \multicolumn{7}{|l|}{ II - Skills in BP measurement } \\
\hline A. Preparation for the procedure & 58.61 & 2.90 & 60.39 & 3.33 & 1.78 & 694 \\
\hline B. Techniques & 60.48 & 5.39 & 58.52 & 5.06 & -1.96 & .673 \\
\hline $\begin{array}{l}\text { C. Recording, interpretation, and referral based on } \\
\text { JNC } 7 \text { BP classification }\end{array}$ & 59.00 & 0,43 & 60.00 & 0.46 & 1.00 & .317 \\
\hline D. Device quality check & 61.81 & 3.15 & 57.19 & 3.17 & -4.62 & .434 \\
\hline E. For 1st BP examination & 31.02 & 0.30 & 27.50 & 0.00 & -3.52 & .074 \\
\hline F. For elevated initial BP taken & 28.10 & 0.77 & 30.08 & 0.78 & 1.98 & .570 \\
\hline G. For subsequent BP examination & 51.64 & 0.45 & 57.96 & 0.74 & 6.32 & .099 \\
\hline
\end{tabular}

* Statistically significant at $\alpha 0.05$

Table 5. Public health nurses' adherence to BP measurement guidelines before and after intervention

\begin{tabular}{|c|c|c|c|c|c|c|c|c|c|c|}
\hline \multirow[b]{2}{*}{ Outcome Variable } & \multicolumn{4}{|c|}{ Intervention $(n=59)$} & \multicolumn{4}{|c|}{ Control $(n=59)$} & \multicolumn{2}{|c|}{2 Groups } \\
\hline & $\begin{array}{c}\text { Mean } \\
\text { Rank (\%) } \\
\text { Pre-test }\end{array}$ & $\begin{array}{c}\text { Mean } \\
\text { Rank (\%) } \\
\text { Post-test }\end{array}$ & $\begin{array}{l}\text { Standard } \\
\text { Deviation }\end{array}$ & $p$ value & $\begin{array}{c}\text { Mean } \\
\text { Rank (\%) } \\
\text { Pre-test }\end{array}$ & $\begin{array}{c}\text { Mean } \\
\text { Rank (\%) } \\
\text { Post-test }\end{array}$ & $\begin{array}{l}\text { Standard } \\
\text { Deviation }\end{array}$ & $p$ value & $\begin{array}{l}\mathrm{p} \text { - value } \\
\text { Pre-test }\end{array}$ & $\begin{array}{l}\mathrm{p} \text {-value } \\
\text { Post-test }\end{array}$ \\
\hline $\begin{array}{l}\text { I - Knowledge of } \\
\text { BP measurement Guidelines }\end{array}$ & 56.83 & 70.52 & 3.21 & $<0.001^{*}$ & 62.17 & 48.48 & 2.69 & .225 & .240 & $<0.001^{*}$ \\
\hline \multicolumn{11}{|l|}{ II - Skills in BP measurement } \\
\hline $\begin{array}{l}\text { A. Preparation for BP measurement } \\
\text { procedure }\end{array}$ & 58.61 & 70.69 & 4.64 & $<0.001^{*}$ & 60.39 & 48.31 & 2.98 & .213 & .694 & $<0.001^{*}$ \\
\hline B. Techniques & 60.48 & 76.61 & 7.80 & $<0.001^{*}$ & 58.52 & 42.79 & 4.74 & .835 & .673 & $<0.001^{*}$ \\
\hline $\begin{array}{l}\text { C. Recording, interpretation, and } \\
\text { referral based on JNC } 7 \\
\text { BP classification }\end{array}$ & 59.00 & 59.50 & 0.58 & 1.000 & 60.00 & 59.50 & 0.81 & .317 & .317 & 1.000 \\
\hline D. Device quality check & 61.81 & 71.42 & 3.23 & 0179 & 57.19 & 47.58 & 3.27 & .146 & .434 & $<0.001^{*}$ \\
\hline E. For 1st BP examination & 31.02 & 15.88 & 1.04 & 0.317 & 27.50 & 11.65 & 0.55 & .317 & .074 & $0.036^{*}$ \\
\hline F. For elevated initial BP taken & 28.10 & 30.92 & 0.89 & 0.584 & 30.08 & 30.08 & 0.86 & .584 & .570 & $0.036^{*}$ \\
\hline G. For subsequent BP examination & 51.64 & 67.30 & 0.96 & $0002^{*}$ & 57.96 & 48.54 & 0.00 & .186 & .099 & $<0001^{*}$ \\
\hline
\end{tabular}

* Statistically significant at $\alpha-0.05$

The range of patients seen for BP taking and the number of BP measurements done daily may easily shift depending on the activities and health programs of the Department of Health, and the Local Government Units. The volume of patients was reported to cause stress which may increase the tendency to disregard recommended guidelines and compromise BP measurement accuracy. Practice variations among clinic nurses, PHNs, and community health nurses are generally attributed to their hectic and stressful work situation. ${ }^{4,12}$

There is homogeneity in the level of adherence to the guidelines between groups at baseline $(p=>.05)$. Baseline score of study participants were $\leq 62 \%$ in knowledge of the BP measurement guidelines, and skills in: 1) preparation for procedure, 2) BP measurement device quality check, 3) BP measurement techniques, 4) $1^{\text {st }} \mathrm{BP}$ examination, 5) elevated initial BP examination, 6) subsequent BP examination, 7) recording, interpretation, and referral based on JNC 7 BP classification. These data are summarized in Table 4.

Knowledge scores at baseline were compared to the findings of Armstrong et $\mathrm{al}^{6}$ where no item got a $100 \%$ response. This study was also similar to that of Dickson and
Hajjar $^{21}$ where only two of the five community health nurses passed the knowledge test at baseline.

Scores of BP measurement skills at baseline confirmed the findings of Drevenhorn et al. ${ }^{29}$ where 21 PHNs who performed $3 \mathrm{BP}$ measurements were evaluated based on standardized measurement. Study showed lower scores in 10 areas: 1) documentation of the time of day, 2) palpating the pulse while inflating the bladder, 3) unbroken rest for 5 minutes or more, 4) documentation of each arm used, 5) registration at even 2 numbers, 6) right cuff size, 7) not inflating the bladder while deflating, 8) equipment calibrated, 9) palm turned upwards, and 10) patient's legs not crossed. The participants of this study performed $100 \%$ only in positioning the arm at heart level, and correct application of cuff. This implies the need to standardize training and retraining of health care providers who directly perform BP measurements.

Post-test scores of both groups are summarized in Table 5. The intervention group showed a significant increase in the level of adherence based on knowledge of BP measurement guidelines $(p=<.001)$, and skills in: 1) preparation for the procedure $(p=<.001)$; 2) technique $(p=<.001)$; and 3) subsequent BP examination $(p=<.002)$. The 
increase was not significant in: 1) BP device quality check, and 2) elevated initial BP examination. No change was shown in recording, interpretation, and referral based on JNC7 BP classification, and 1st BP examination. The posttest scores of the control group showed no significant difference from their baseline level of adherence in all the outcome variables. When compared, the post-test scores of the intervention group were significantly higher in most of the outcome variables $(p=<.05)$, i.e., in knowledge of BP measurement guidelines, and skills in 1) preparation, 2) technique, 3) device quality check, and 4) subsequent BP examination. Both groups showed no significant difference in the skill in recording, interpretation, and referral based on JNC7 guidelines.

This study supports findings of other studies that training and awareness of the guidelines will not guarantee BP measurement practices to follow established guidelines. ${ }^{2,4,6,12,19}$ Other studies also show that the practices of community health nurses improve towards adherence based on the observer's knowledge or training on the guidelines, the equipment used, and the work setting. ${ }^{19}$

\section{Limitation of the Study}

The characteristic of the study participants which is inherent to their complex role in the community and the very nature of their specific setting limit the external validity of findings. Generalization to other population must be done with caution.

\section{Implications of the study}

Performing BP measurements that adhere to the guidelines strengthens a standardized practice, limits inaccuracies, and becomes a more meaningful assessment tool for the prevention, control, and management of hypertension. Existing programs on health promotion and NCD prevention and control, safety, standards, efficiency, and quality care may benefit from BPMTP. BPMTP may have added value when integrated into nursing foundation courses where practice standards and accuracy are given serious attention. It is possible to objectively measure adherence to BP measurement guidelines based on knowledge of the guidelines, and skills in BP measurement with existing reliable and valid tools.

\section{Conclusion}

Practice variations exist and pitfalls in BP measurement could easily be overlooked or neglected. Our data show that the implementation of a BPMTP is feasible and improves adherence to BP measurement guidelines with higher level of knowledge of the guidelines and skills in BP measurement. While BPMTP improved adherence of BP measurement to the guidelines, special attention must be given to skills in BP recording, interpretation, and referral by both groups, BP measurement device quality checklist, 1st clinic visit, and elevated 1st BP reading on clinic visit. Low adherence may be multi-factorial which may require a collaborative effort to examine and fully address them, considering its impact to health and care services. A largerscale randomized clinical trial is warranted to show that BPMTP can potentially improve clinical management of hypertension in public health clinics globally.

\section{Recommendations}

1. Adopt a regularly administered "step-by-step"/ "competency-based" BP measurement protocol based on current guidelines for the nursing foundations and in all related courses.

2. Include BPMTP as part of quality assurance processes, to include accurate and efficient system of recording, and dissemination of acceptable guidelines, and algorithms to simplify and coordinate nursing actions.

3. Replicate the study to a bigger population of nurses, with longer intervention time, and repeated evaluation period to determine sustainability of positive adaptation of $\mathrm{BP}$ measurement practices that adhere to the guidelines.

\section{Statement of Authorship}

All authors have approved the final version submitted.

\section{Author Disclosure}

All authors declared no conflict of interest.

\section{Funding Source}

This paper was partially funded by the UP College of Nursing Foundation, Inc.

\section{References}

1. National League of Philippine Government Nurses, Inc. Public Health Nursing in the Philippines, 10th ed. 2007.

2. Chobanian AV, Bakris GL, Black HR, et al. Seventh Report of the Joint National Committee on Prevention, Detection, Evaluation, and Treatment of High Blood Pressure. Hypertension. 2003; 42(6):1206-52.

3. Padwal RS, Hemmelgam BR, Khan NA, et al. The 2009 Canadian Hypertension Education Program recommendations for the management of hypertension: Part 1 - blood pressure measurement, diagnosis and assessment of risk. Can J Cardiol. 2009; 25(5):279-86.

4. Pickering TG, Hall JE, Appel LJ, et al. Recommendations for blood pressure measurement in humans and experimental animals, part I: blood pressure measurement in humans: a statement for professionals from the Subcommittee of Professional and Public Education of the American Heart Association Council on High Blood Pressure Research. Circulation. 2005; 111(5):697-716.

5. Ritchie LD, Campbell NC, Murchie P. New NICE guidelines for hypertension. BMJ. 2011; 343:d5644.

6. Armstrong RS. Nurses' knowledge of error in blood pressure measurement technique. Int J Nurs Pract. 2002; 8(3):118-26. 
7. Jones DW, Appel LJ, Sheps SG, Roccella EJ, Lenfant C. Measuring blood pressure accurately: New and persistent challenges. JAMA. 2003; 289(8):1027-30.

8. National Kidney Foundation, K/DOQI, Clinical Practice Guidelines on Hypertension and Antihypertensive Agents in Chronic Kidney Disease, Guideline 3: Measurement of Blood Pressure in Adults [Online]. 2004 [cited 2011]. Available from http://www.kidney.org/professionals/ kdoqi/guidelines_bp/guide_3.htm

9. Nolan J, Nolan M. Can nurses take an accurate blood pressure? Br J Nurs. 1993; 2(14):724-9.

10. O'Brien E, Mee F, Tan KS, Atkins N, O'Malley K. Training and assessment of observers for blood pressure measurement in hypertension research. J Hum Hypertens. 1991; 5(1):7-10.

11. Clark CE, Taylor RS, Shore AC, Campbell JL. The difference in blood pressure readings between arms and survival: Primary care cohort study, BMJ. 2012; 344:e1327. doi: 10.1136/bmj.e1327

12. Minor DS, Butler KR Jr, Artman KL, et al. Evaluation of blood pressure measurement and agreement in an academic health sciences center. J Clin Hypertens (Greenwich). 2012; 14(4):222-7.

13. O'Brien E, Asmar R, Beilin L, et al., on behalf of the European Society of Hypertension Working Group on Blood Pressure Monitoring. European Society of Hypertension recommendations for conventional, ambulatory and home blood pressure measurement. J Hypertens. 2003; 21(5):821-48.

14. Parati G, Bilo G, Mancia G. Blood pressure measurement in research and in clinical practice: recent evidence. Curr Opin Nephrol Hypertens. 2004; 13:343-57.

15. Gillespie A, Curzio J. Blood pressure measurement: Assessing staff knowledge. Nursing Standard. 1998; 12(23):35-7.

16. Hinckley P, Walker S. Measuring blood pressure. Practice Nurse. 2005; 29(9):54-61.

17. Philippine Society of Hypertension. 140/90 report: Multisectoral task force consensus on Hypertension. 2011. Unpublished.

18. Torrance C, Serginson E. Student nurses' knowledge in relation to blood pressure measurement by sphygmomanometry and auscultation. Nurse Educ Today. 1996; 16(6):397-402.

19. Dickson BK, Hajjar I. Blood pressure measurement education and evaluation program improves accuracy in community-based nurses: A pilot study. J Am Acad Nurse Pract. 2007; 19(2):93-102.
20. Parati G, Stergiou GS, Asmar R, et al., on behalf of ESH Working Group on Blood Pressure Monitoring. European Society of Hypertension guidelines for blood pressure monitoring at home: A summary report of the Second International Consensus Conference on Home Blood Pressure Monitoring. J Hypertens. 2008; 26(8):1505-26.

21. Roy C. Adaptation: A conceptual framework for nursing. Nurs Outlook. 1970; 18(3):42-5.

22. Roy C. Introduction to Nursing: An Adaptation Model (2nd edition) [Online]. 1984 [cited 2011]. Available from http://currentnursing.com/ nursingtheory/application_Roy\%27s_adaptation_model.html

23. World Health Organization-Global Health Observatory (WHO-GHO) World Health Statistics 2012 [Online]. 2012 [cited 2012]. Available from http://www.who.int/gho/publications/world_health_statistics/2012/en/in dex.html

24. Balabagno AO, Cuevas FP, Laurente $\mathrm{CM}$, et al. Clinical practice guidelines on hypertension detection and control for nurses and midwives. Manila: DOH. 2002.

25. Villegas I, Arias IC, Botero A, Escobar A. Evaluation of the technique used by health-care workers for taking blood pressure. Hypertension. 1995; 26(6 Pt 2):1204-6.

26. Himmelfarb CR, Commodore-Mensah Y, Hill MN. Expanding the Role of Nurses to Improve Hypertension Care and Control Globally. Ann Glob Health. 2016; 82(2):243-53.

27. Grim C. Importance of accuracy: The cost of errors. National High Blood Pressure Education Program (NHBPEP)/National Heart, Lung, and Blood Institute (NHLBI) and American Heart Association Working Meeting on Blood Pressure Measurement. Summary Report. National Institutes of Health, Bethesda, Maryland. 2002.

28. Whitworth JA, World Health Organization, International Society of Hypertension Writing Group. 2003 World Health Organization (WHO)/ International Society of Hypertension (ISH) statement on management of hypertension. J Hypertens. 2003; 21(11):1983-92.

29. Drevenhorn E, Hakansson A, Petersson K. Blood pressure measurement: An observational study of 21 public health nurses. J Clin Nurs. 2001 10(2):189-94.

30. TRUE Consortium. Recommended Standards for Assessing Blood Pressure in Human Research Where Blood Pressure or Hypertension is a Major Focus. Kidney Int Rep. 2017;2(4):733-8. 